\title{
Methods for testing the performance of long-distance wireless power transmission systems
}

\author{
Xudong Wang ${ }^{1}$, Changbo Lu' ${ }^{1}$ Changfu Wang ${ }^{1}$, Panpan Liu' ${ }^{1}$ Wanli Xu ${ }^{1 *} \mathbb{0}$, Youjie Zhou ${ }^{1}$ and Feng Wang ${ }^{2}$
}

*Correspondence:
xuwl06@163.com
${ }^{1}$ Institute of System
Engineering, Academy
of Military Science,
Beijing 100300, China
Full list of author information
is available at the end of the
article

${ }^{*}$ Correspondence: xuwl06@163.com Engineering Academy of Military Science, Full list of author information article

\begin{abstract}
Long-distance wireless power transmission can reduce the dependence of unmanned systems on energy storage systems, which is especially advantageous for unmanned aerial vehicles. This approach is key for building an integrated and uninterrupted airto-ground power supply network. This paper introduces the technical characteristics of long-distance wireless power transmission systems, reports the development of such systems at home and abroad, and proposes technical indices and methods for performance evaluation of these systems. A test was conducted using a testing device, and the key parameters of the system performance were obtained. This work provides a solid foundation for the performance evaluation studies of long-distance wireless power transmission systems.
\end{abstract}

Keywords: Wireless power transmission, Long-distance, Laser, Microwave, Testing method

\section{Introduction}

Wireless power transmission technology refers to a brand-new mode of power supply, whereby power can be transmitted without cables. Using lasers and microwaves as vectors, long-distance wireless power transmission technology can be applied to terrestrial power distribution systems, space energy utilization, unmanned networking, and unmanned clusters. Wireless transfer of power between subsystems and "unlimited" power supply for weapons equipment can be achieved in principle. This paper mainly analyzes the technical characteristics of laser wireless power transmission and microwave wireless power transmission systems, and proposes two types of methods for testing the performance of such wireless power transmission systems. Compared with the existing methods, our methods has the following advantages: (1) The components and systems are tested respectively, and the size, power and efficiency evaluation indexes are put forward; (2) According to the evaluation index, the specific measuring point position, testing instrument and testing process are put forward; (3) The wireless energy transmission system has greater power and longer transmission distance, which has more practical reference significance. In addition, a performance test that uses a testing author(s) and the source, provide a link to the Creative Commons licence, and indicate if changes were made. The images or other third party material in this article are included in the article's Creative Commons licence, unless indicated otherwise in a credit line to the material. If material is not included in the article's Creative Commons licence and your intended use is not permitted by statutory regulation or exceeds the permitted use, you will need to obtain permission directly from the copyright holder. To view a copy of this licence, visit http:// creativecommons.org/licenses/by/4.0/. 
device is carried out, some key parameters such as power and efficiency are obtained, which provides the basis for the subsequent development of relevant work.

\section{Related work}

The long-distance wireless power transmission technology mainly considers laser wireless power transmission and microwave wireless power transmission systems. The principle of laser wireless power transmission is the transmitting end converts the electrical energy into a laser beam using a photoelectric device, and the receiving end converts the laser beam energy back into electrical energy. Its merits are long transmission distance, strong directivity, small transceiver antenna aperture, concentrated energy. Its shortcomings are high energy consumption, sensitivity to clouds and obstacles, low transmission efficiency. Laser wireless power transmission is commonly used for unmanned aerial vehicles, microsatellites, space probes, wireless sensor networks. Microwave wireless power transmission's transmitter uses a vacuum device to convert the electrical energy to microwaves, and the receiver uses a rectifier to convert the microwaves to direct current. Its merits are large transmission power, small transmission loss in the atmosphere, one-to-many transmission. Its shortcomings are large scattering loss, jamming communication equipment, low efficiency, large antenna aperture. Microwave wireless power transmission is commonly used for distributed satellite platforms, solar power stations, deep space exploration.

\subsection{Laser wireless power transmission}

In the laser-based wireless power transmission process, the electrical energy in a power grid or energy storage unit is converted by a laser power source and is provided to a laser. The laser converts the electrical energy into a laser beam, which is captured by a photovoltaic array. The laser output is converted into electrical energy at the receiving end after free-space transmission [1]. The laser-based wireless power transmission technology is advantageous owing to its high energy density, strong energy convergence, strong directivity, long transmission distances, and small transmission/reception aperture (only $10 \%$ of that of a typical microwave wireless power transmission system). After long-distance transmission, the laser beam is still concentrated and suitable for powering long-distance mobile devices [2]. Therefore, laser-based energy transmission can be used for ground electric energy distribution, spatial scientific research, spatial energy utilization, and concealed spatial communications. It provides energy for mobile electric equipment such as mobile base stations, unmanned aerial vehicles (UAVs), airships, robots, deep-space probes, and module spacecraft.

In 2004, inspired by concentration cells, Howell [3] designed a receiver for laser-based power transmission signals. On the front surface of a GaAs photovoltaic cell (diameter, 4 $\mathrm{mm}$ ), a lens (diameter, $3.7 \mathrm{~cm}$ ) was used for collecting light. In the experiment, the laser wavelength was $830 \mathrm{~nm}$ and the power was $0.52 \mathrm{~W}$. The optimized photoelectric conversion efficiency of the laser-receiving system was above $56 \%$. In 2010, the US Naval Laboratory [4] simulated the effects of different laser power densities on the characteristics of InGaP/GaAs/Ge triple-junction solar cells, which were irradiated by three laser systems (wavelengths at $555 \mathrm{~nm}, 860 \mathrm{~nm}$, and $1510 \mathrm{~nm}$ ). The objective was to optimize the laser wavelength and power density through calculations. In 2013, He [5] reported a laser power 
transmission ground system for studying the energy transmission efficiency. Using this system, the effects of the laser wavelength and different photovoltaic device materials on the energy transmission efficiency were quantified. In 2014, Qiao and co-workers [6] studied the effects of the laser wavelength and laser power density on the energy conversion efficiency of GaAs photovoltaic cells. In their experiment, lasers with the wavelengths of 532 $\mathrm{nm}, 671 \mathrm{~nm}, 808 \mathrm{~nm}$, and $980 \mathrm{~nm}$ irradiated GaAs batteries at $2 \mathrm{~m}$, and the photoelectric conversion efficiency of the irradiated GaAs batteries exhibited a single-peak characteristic as a function of the laser power density.

\subsection{Microwave wireless power transmission}

In the microwave-based wireless power transmission (MWPT) process, the city power system completes the conversion of high-voltage direct current (DC) through a power supply. Alternating current $(\mathrm{AC})$ is converted into microwaves by a vacuum device, and the resulting waves are emitted using a transmitting antenna. Using a rectifying device, the receiving antenna receives and converts the microwave energy into DC power output [7]. The output power range is $10-100 \mathrm{~kW}$; the transmission distance range is $1-20 \mathrm{~km}$. The microwavebased wireless power transmission technology is advantageous owing to its high transmission power, strong environmental adaptability, flexible focusing and scattering, high conversion and transmission efficiency, low atmospheric loss, and strong penetration. This technology can be used for high-precision controlled beam pointing. With high security, it is suitable for powering long-distance unmanned equipment and for information exchange in complex environments. It can also be used for ground power distribution, space energy utilization, and microsensor-based energy communications, providing fast and convenient energy requirements for mobile electrical equipment such as microsensors, drones, and distributed satellites [8].

In 1984, Brown applied the plane technology to designing a rectifier antenna for microwave wireless power transmission systems [9], in which the receiving antenna was a planar dipole and the rectifier diode was directly connected to two metal strip lines (the so-called CPS transmission line). Later, Chang and co-workers applied a CPS-feeding dual rhombic loop to the receiving antenna. This loop had high gain, broadband, and circular polarization characteristics. In 2014, Yang and co-workers [10] published a review on the two types of rectifier antenna elements and arrays. AC-band MWPT system was designed for meeting the requirements of high beam capture efficiency to the distribution of the transmitting antenna aperture. Japanese Mitsubishi researchers converted $10 \mathrm{~kW}$ of electricity into microwaves and used wireless power transmission to successfully power light-emitting diodes (LEDs) on the receiving device, from a distance of $500 \mathrm{~m}$. From 2008 to 2011, technical research has been performed in the US about the ground microwave wireless power transmission tests at a distance of $100 \mathrm{~km}$, an airship energy supply test for a height of 20 $\mathrm{km}$, a space solar power station platform ground test for $100 \mathrm{~kW}$, and a microwave driven lunar rover ground test for $20 \mathrm{~kW}$ [11]. 


\section{Methods}

\subsection{Methods for testing the laser wireless power transmission systems}

\subsubsection{Testing index}

Technical indexing can be divided into transmitter, space transmission, and receiver indices, according to the system composition, and it can also be divided into size, power, and efficiency indexing, according to the index type. The technical indexing system is shown in Fig. 1. In practical applications, a laser-based wireless power transmission system needs to focus on the miniaturization and weight reduction of the receiving end. The transmitting aperture, the size of the receiving photovoltaic cell array, and the transmission distance are typically used as size indicators, and then the power at each node of the transmitting/receiving system is measured. The transmission efficiency of the system can be obtained from calculations.

\subsubsection{Testing methods}

The experiment adopted a fiber-coupled semiconductor laser with adjustable power. The laser wavelength was $808 \mathrm{~nm}$. The laser was connected to a collimated beam expansion system through an optical fiber; then, the laser beam was irradiated on a 43 $\times 43 \mathrm{~cm}^{2}$ photovoltaic cell array, and the power was supplied to the load after passing through a photoelectric converter and a rectifier regulator. During the test, an infrared viewer was used for observing the laser beam and the light spot on the photocells array. A digital multimeter measured the DC power supply at the input end of the semiconductor laser. An optical power meter measured the optical power of the laser output through the fiber. The output current and output voltage were measured using an electronic load. The test process was conducted as follows. First, the laser power supply was started and the temperature of the semiconductor laser was stabilized at

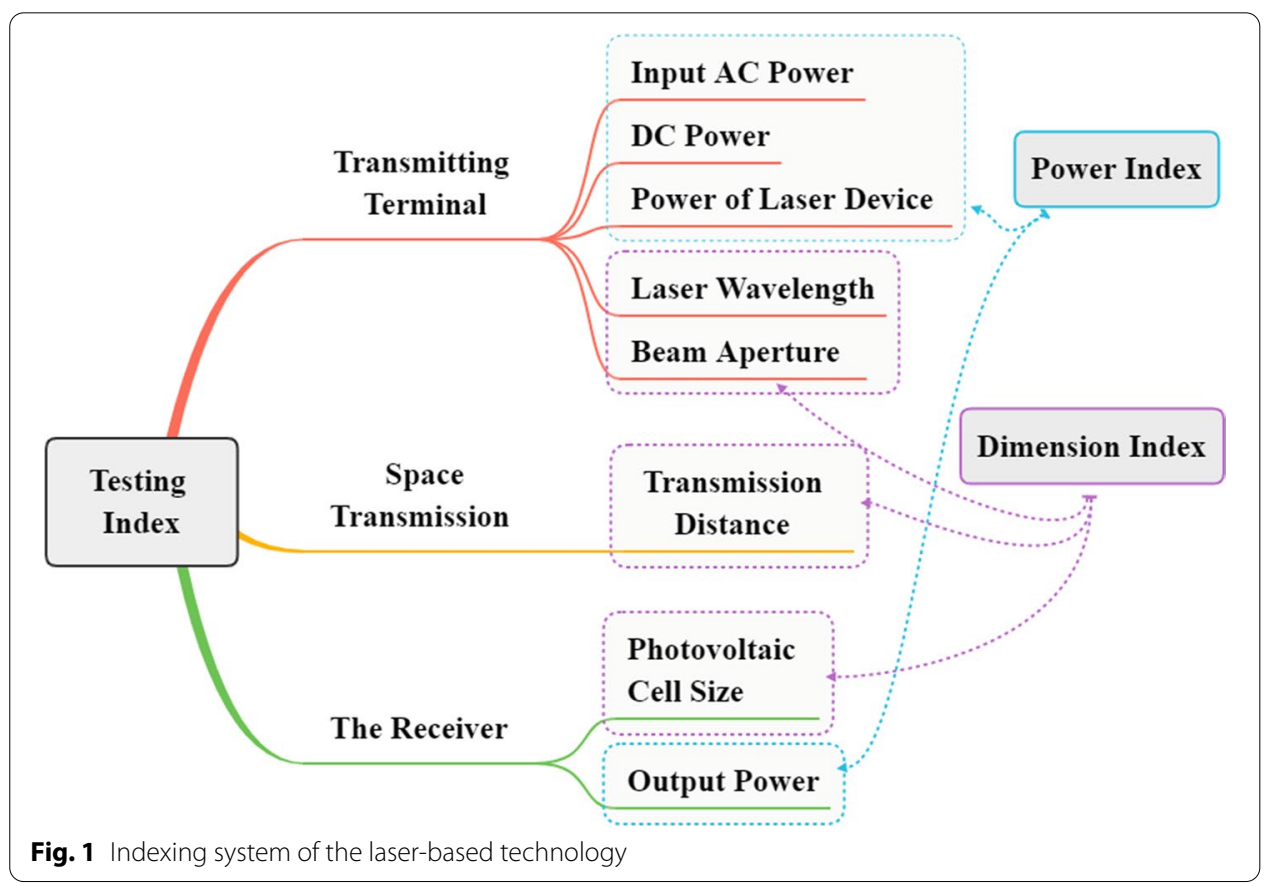



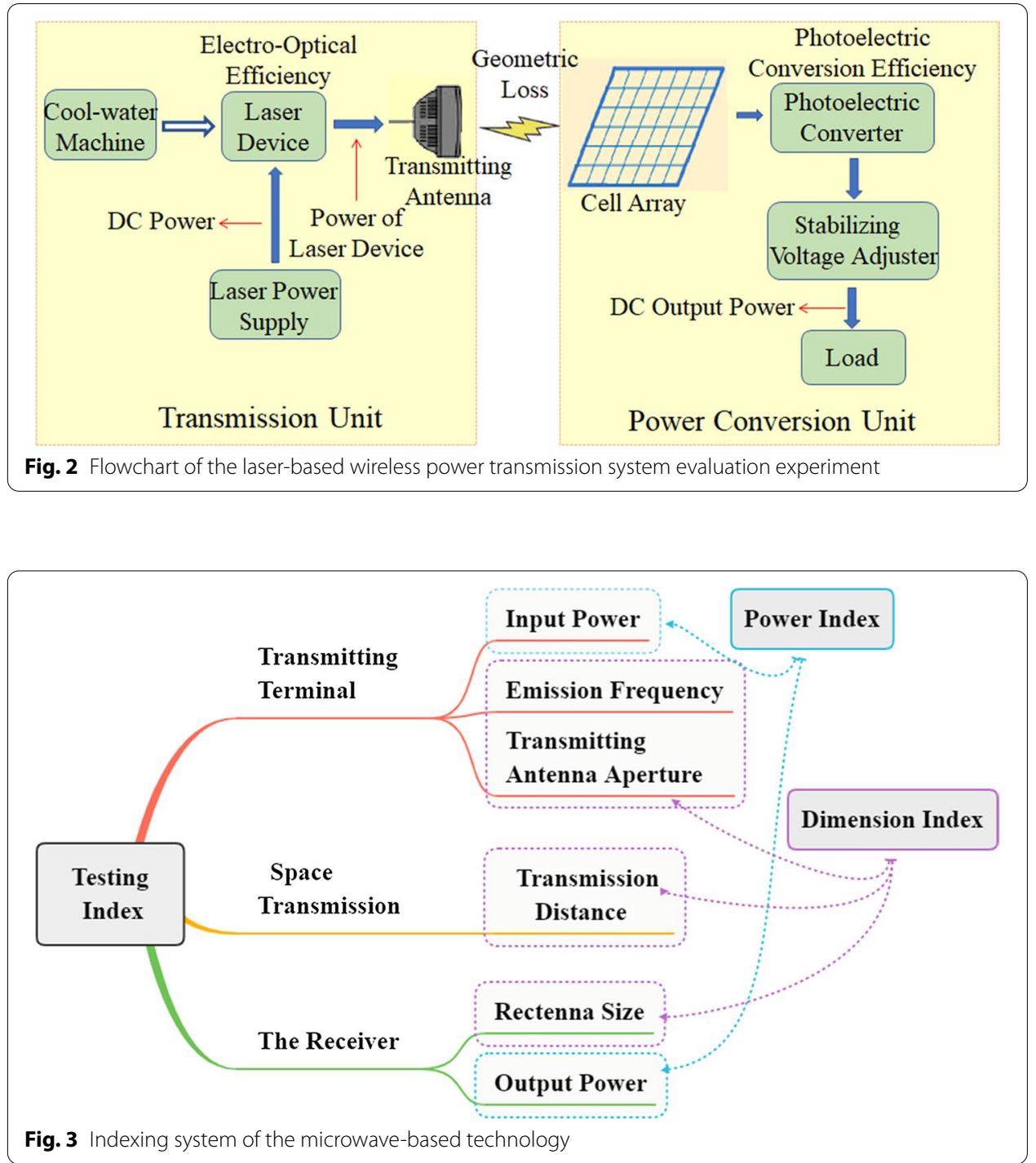

$25{ }^{\circ} \mathrm{C}$ using a cool-water machine. Next, the system input AC power was adjusted, and the light spot in the center of the probe was determined using an infrared viewer, allowing to point the optical power meter to the fiber. The output power of the laser was measured for different input power values, and the current and voltage at the output end of the rectifier regulator were measured for obtaining DC output power. The test procedure is shown in Fig. 2.

\subsection{Methods for testing the microwave wireless power transmission systems}

\subsubsection{Testing index}

The microwave technical indexing system can be divided into transmitter, space transmission, and receiver types, according to the system composition. It can further be divided into size, power, and efficiency indexing, according to the index type. The technical indexing system is shown in Fig. 3. 


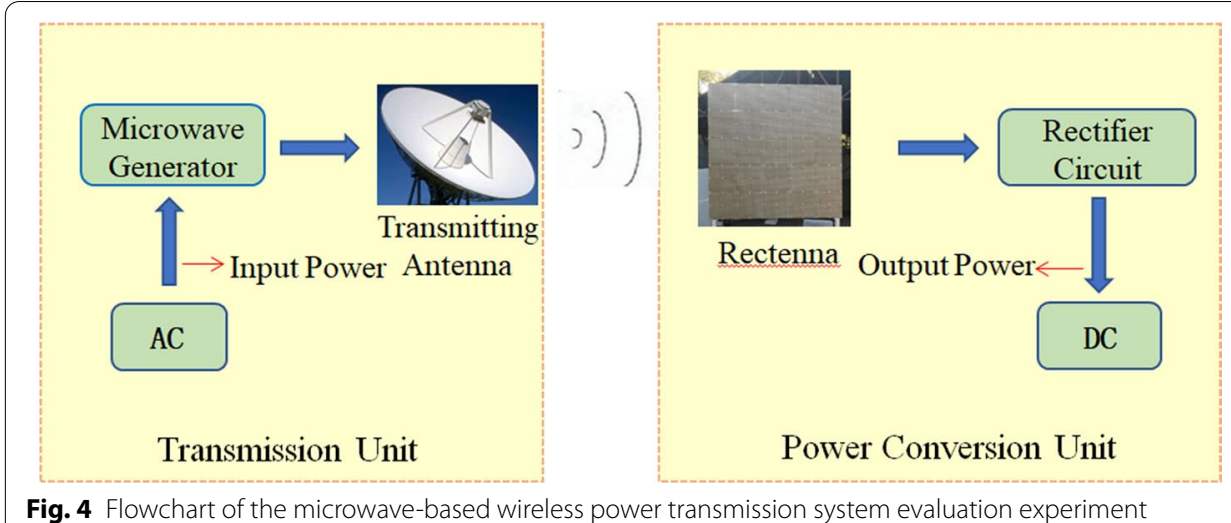

Fig. 4 Flowchart of the microwave-based wireless power transmission system evaluation experiment

Table 1 Test conditions

\begin{tabular}{lll}
\hline & Parameter & Value \\
\hline 1 & Transmission distance & $50 \mathrm{~m}$ \\
2 & Cell array size & $430 \times 430 \mathrm{~mm}^{2}$ \\
3 & Beam aperture & $44 \mathrm{~mm}$ \\
4 & Wavelength & $808 \mathrm{~nm}$ \\
\hline
\end{tabular}

\subsubsection{Testing methods}

A vacuum device (klystron) converted the alternating current into microwaves. The microwaves were efficiently transmitted after being focused by a Cassegrain transmitting antenna (aperture, $1.6 \mathrm{~m}$ ). The receiving end used a $2 \times 2 \mathrm{~m}^{2}$ antenna, to connect a rectifier device (cyclotron-wave rectifier), and converted the microwave power into the DC output power [12]. During the test, a digital multimeter was used for measuring the power input to the microwave power generator, and an electronic load was used for determining the output current and output voltage of the rectifier circuit.

The test process was conducted as follows. First, the system input power was adjusted and recorded. Next, the output current and voltage were measured for different input power values. From the obtained power data, the power conversion efficiency of the system for different input power values was calculated. The workflow of the test procedure is shown in Fig. 4.

\section{Results and discussion}

\subsection{Testing examples and analysis of laser wireless power transmission systems}

According to the test conditions in Table 1, both the laser performance and the system performance were tested.

\subsubsection{Performance tests of lasers}

The output characteristics and conversion efficiency of the laser, for different input powers, are shown in Table 2. According to the data in the table, the relationship 
Table 2 Test results of the laser-based wireless power transmission system

\begin{tabular}{lllllll}
\hline \multirow{2}{*}{ Parameter } & \multicolumn{7}{l}{ Measured values } \\
\cline { 3 - 7 } & & Group 1 & Group 2 & Group 3 & Group 4 & Group 5 \\
\hline 1 & System input AC power (W) & 139.2 & 239.4 & 341.3 & 453.2 & 579.5 \\
2 & DC power of laser (W) & 73.5 & 152.1 & 235.8 & 323.46 & 414.95 \\
3 & Laser power (W) & 23.17 & 66.01 & 107.7 & 148.7 & 185.3 \\
4 & Electro-optical conversion efficiency of laser & $31.52 \%$ & $43.40 \%$ & $45.67 \%$ & $45.97 \%$ & $44.66 \%$ \\
5 & AC-optical power conversion efficiency & $16.6 \%$ & $27.6 \%$ & $31.6 \%$ & $32.8 \%$ & $32.0 \%$ \\
\hline
\end{tabular}

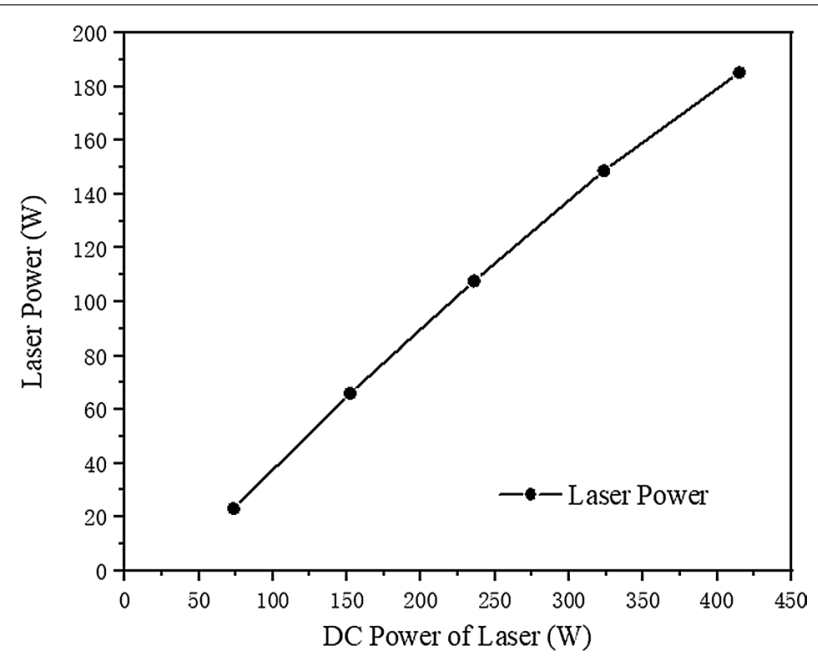

Fig. 5 Input-output relationship for the semiconductor laser-based system

between the output power of the semiconductor laser and the power supply was obtained, and the conversion efficiency waveform was obtained.

Figure 5 shows the output power versus the power supply, for the semiconductor laser. The lasers optical power increases linearly with increasing the DC power supply, and the electro-optical conversion efficiency reaches $46 \%$. The internal loss, series resistance, and threshold current of the semiconductor laser reduce its photoelectric conversion efficiency. Among these, the internal loss is mainly caused by the free carrier loss in the confinement layer and in the quantum well; the resistance of the laser p-type waveguide layer and the free carrier loss in the highly doped p-type confinement layer lead to the high series resistance and high overall loss for this laser [13].

As is shown in Fig. 6, the electro-optical conversion efficiency of the semiconductor laser increases linearly with increasing the power supply, then slowly increases to a peak value, and finally gradually decreases. Assuming that the laser output optical power is $P$, the laser DC supply power is $P_{1}$, the AC to optical power conversion efficiency is $\eta_{1}$, and the rectifier circuit AC-DC conversion efficiency is $\eta_{2}$, it follows that the electro-optical conversion efficiency of the laser is $\eta_{\text {electro-optical }}=P / P_{1}$, and the AC-optical power conversion efficiency is $\eta_{1}=\eta_{\text {electro-optical }} \times \eta_{2}$. As the power supply increased from 73.5 to $323 \mathrm{~W}$, the electro-optical conversion efficiency of 


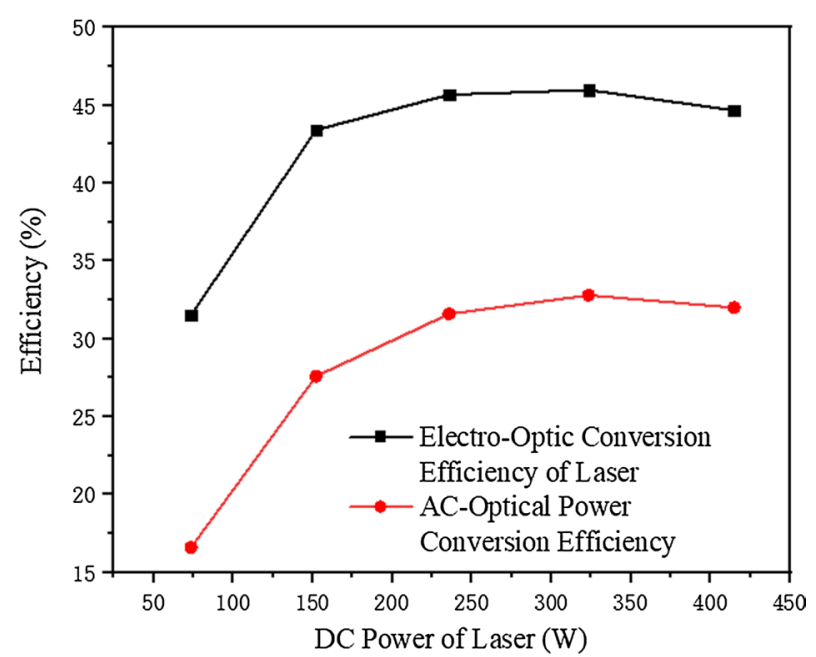

Fig. 6 Semiconductor laser conversion efficiency
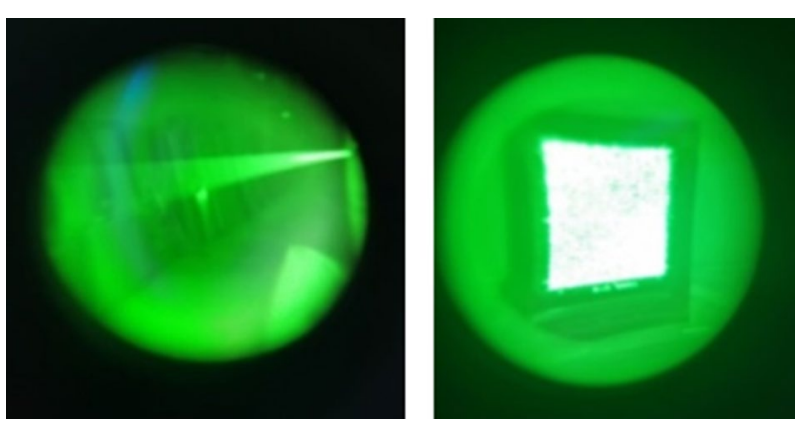

Fig. 7 Laser emission beam and receiving end

the laser increased from $31.5 \%$ to $46 \%$. Subsequently, as the power supply increased to $415 \mathrm{~W}$, the conversion efficiency slowly decreased to $44.6 \%$. The efficiency of the AC-optical power conversion was reduced by $10 \%$, and the waveform was consistent with the trend of the electro-optical conversion efficiency. The energy loss in semiconductor lasers can occur via five routes: (1) Joule heating, (2) carrier leakage, (3) subthreshold spontaneous emission, (4) voltage loss, and 5) photon scattering and carrier absorption loss [14]. As the power supply of the laser increases, the carriers are injected into the active region, and the non-radiative recombination loss and photon scattering loss also increase. The structural parameters of the laser make these mutually restrictive. When an optimal working point is reached, the balance is broken; past the optimal working point, the efficiency starts to decrease slowly [15]. The AC-optical power conversion efficiency exhibits similar trends. The addition of a rectifier module induces a power loss, lowering the efficiency by $10 \%$ compared with the DC electro-optical conversion efficiency. The test results provide a good foundation for optimization studies of high-efficiency laser line arrays and laser-based wireless energy transmission systems. 


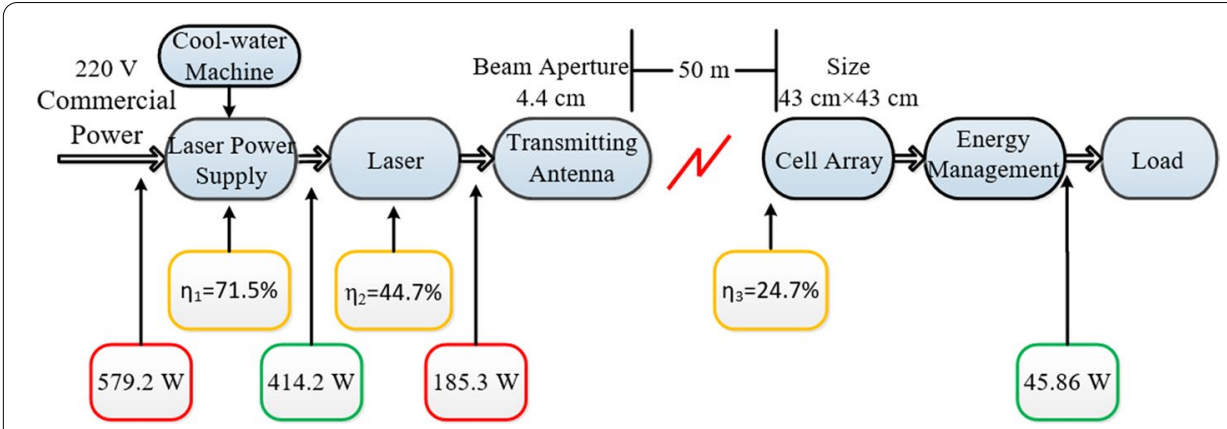

Fig. 8 Diagram of the laser-based wireless power transmission system

Table 3 Microwave test conditions

\begin{tabular}{lll}
\hline & Parameter & Measured values \\
\hline 1 & Transmission distance & $70 \mathrm{~m}$ \\
2 & Working band & $10 \mathrm{GHz}$ \\
3 & Antenna aperture & $1.6 \mathrm{~m}$ \\
3 & Size of rectenna & $2 \times 2 \mathrm{~m}^{2}$ \\
\hline
\end{tabular}

\subsubsection{Performance test of the entire system}

The laser beam and the spot on the cell panel were observed using an infrared viewer, and the spot falling on the center of the probe was calibrated, as shown in Fig. 7.

The measured data in the experiment are shown in Fig. 8. The transmission distance of the laser wireless power transmission system was $50 \mathrm{~m}$, the laser beam aperture was 4.4 $\mathrm{cm}$, the size of the photovoltaic cell array was $43 \times 43 \mathrm{~cm}^{2}$, the system input AC power was $579.2 \mathrm{~W}$, the laser DC power supply was $414.2 \mathrm{~W}$, and the load could stably receive the DC power of $45.86 \mathrm{~W}$; the conversion efficiency of the entire system (AC input to DC output) reached 7.9\%.

By performing the experiment at different input power levels, the power response characteristics of the laser and the energy conversion efficiency trends were obtained. The analysis of these trends revealed that under the irradiation using the 808-nm laser, the output power increased linearly with the input power, and then the increasing trend became weaker; the energy conversion efficiency firstly increased up to the optimal point and then decreased.

\subsection{Testing examples and analysis of microwave wireless power transmission systems}

According to the test conditions in Table 3, a test site was arranged for testing the performance of the microwave wireless power transmission system. The physical device is shown in Figs. 9 and 10.

Table 4 to control sequence lists the output characteristics and conversion efficiency of the system, for different input power values. According to the data in the table, the relationship between the DC output power and the input power was obtained, and the oscillogram plots of the microwave power conversion were generated, as shown in Figs. 11 and 12 respectively. 


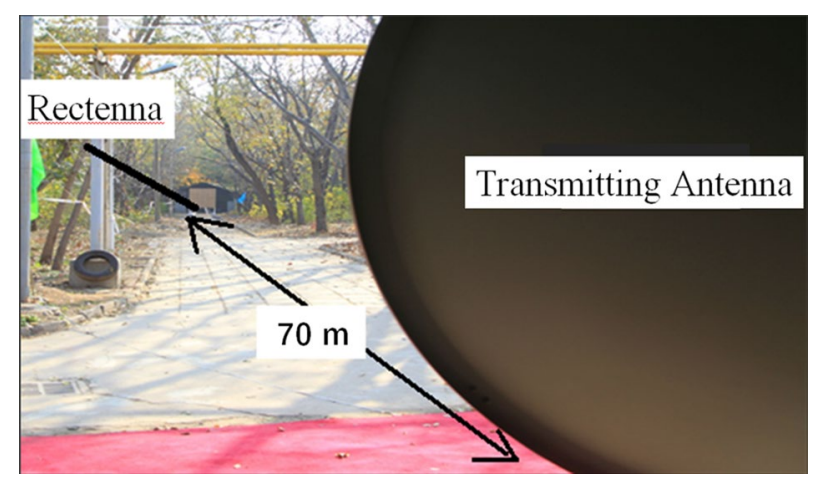

Fig. 9 X band microwave transmission system

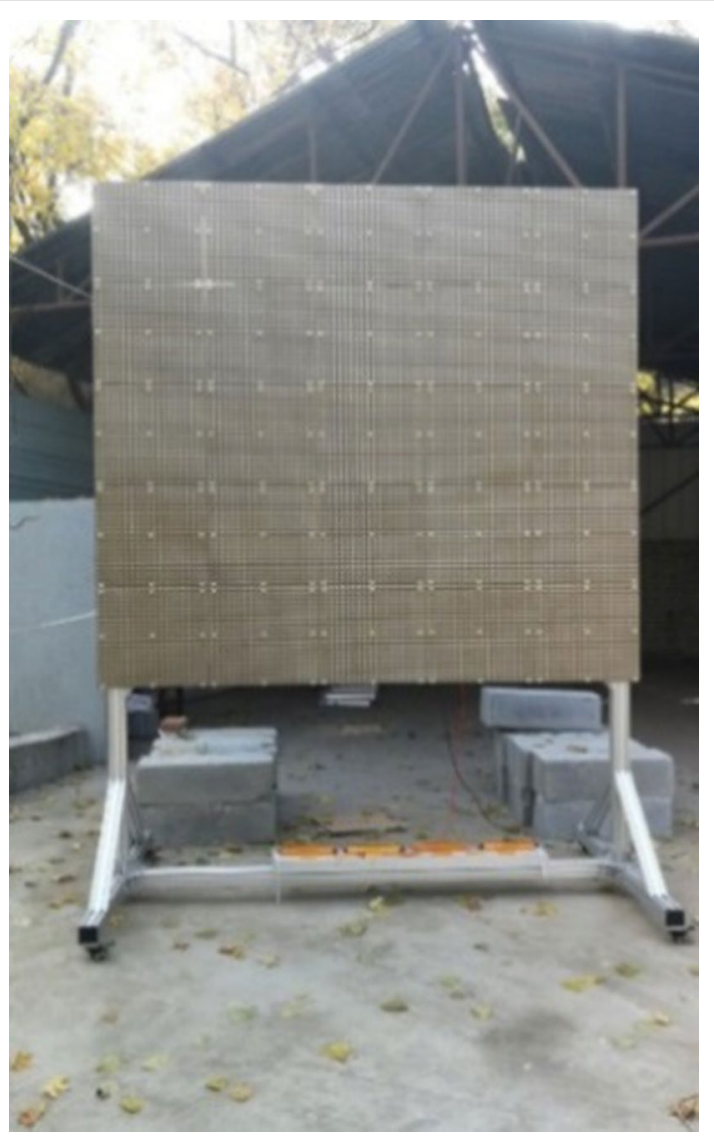

Fig. 10 Rectifier antenna of the receiving end

Table 4 Test data

\begin{tabular}{llllllll}
\hline \multirow{2}{*}{ Parameter } & \multicolumn{2}{l}{ Measured values } \\
\cline { 3 - 7 } & & Group 1 & Group 2 & Group 3 & Group 4 & Group 5 & Group 6 \\
\hline 1 & Input power (W) & 1500 & 2008 & 3060 & 4100 & 4520 & 4580 \\
2 & DC output power (W) & 122.2 & 167.6 & 273.5 & 381.0 & 456.6 & 440.5 \\
3 & Transmission efficiency & $8.15 \%$ & $8.35 \%$ & $8.94 \%$ & $9.29 \%$ & $10.10 \%$ & $9.62 \%$ \\
\hline
\end{tabular}




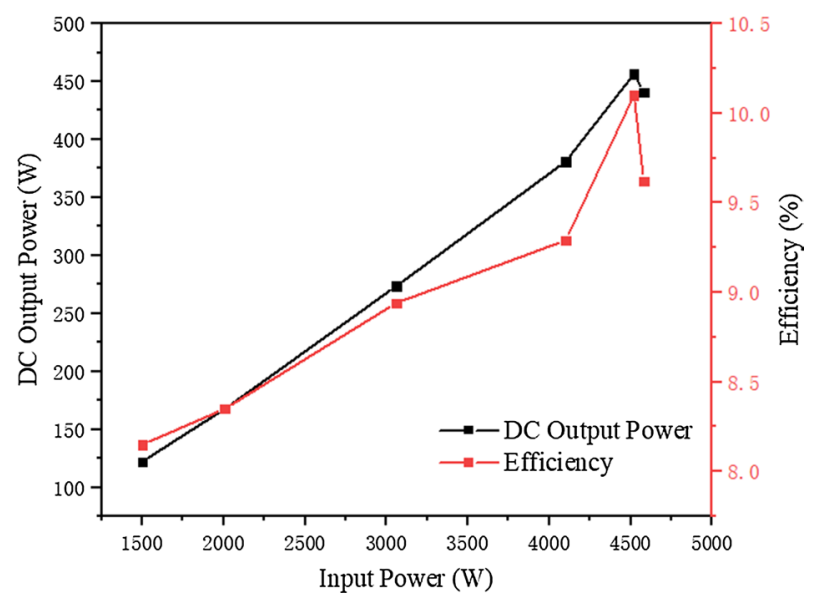

Fig. 11 Input-output power conversion results

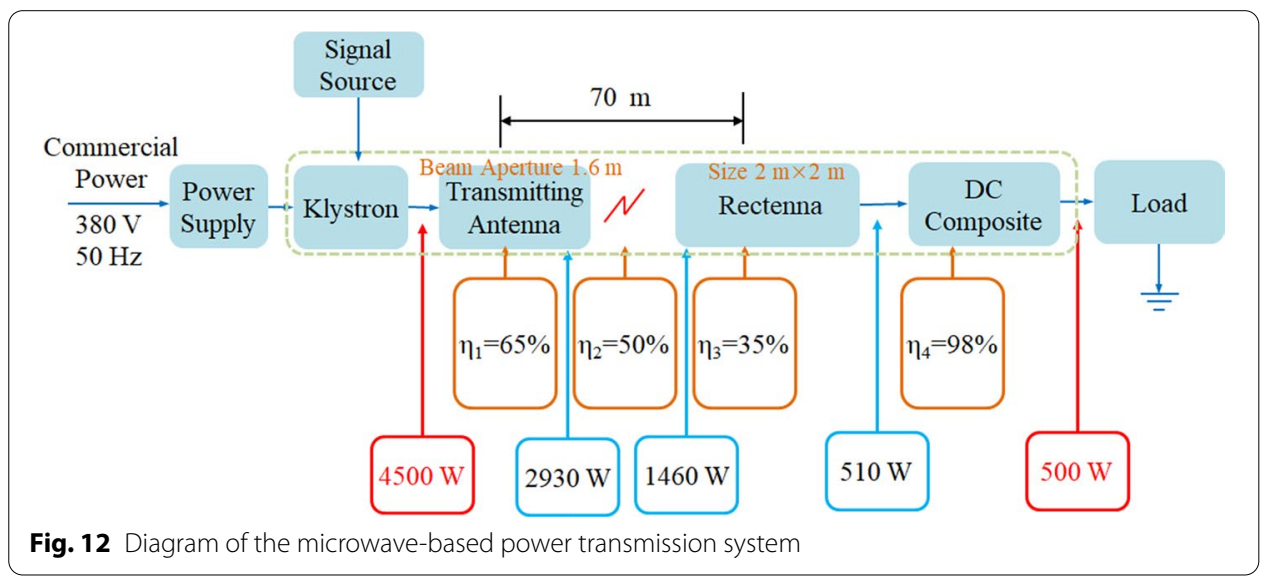

As shown in Fig. 11, the DC output power of the rectenna increased with increasing the system input power. After the input power reached $4500 \mathrm{~W}$, the output power started to decrease. The conversion efficiency waveform trend was similar, reaching a maximal efficiency of $10.4 \%$ at $4500 \mathrm{~W}$, and then decreasing as the input power further increased. The optimal working power of the power transmission system was determined as $4500 \mathrm{~W}$.

The systems efficiency first increased linearly and then decreased. This occurred because the power amplifier in the microwave power generator responded nonlinearly for strong signals, and its nonlinearity increased with increasing the input power, probably yielding nonlinear indices such as gain compression, intermodulation distortion, and harmonic distortion. In addition, the power consumed by the power amplifier accounts for half or more of the energy consumed by the system, and the dissipated power increases the temperature of the power tube and the cavity. The increasing temperature affects the performance of the power amplifiers gain, gain flatness, and linearity; thus, affecting the systems transmission efficiency [16].

The partial data measured in the experiment are shown in Fig. 12. 
The transmission frequency of the high-power microwave transmission system was 10 $\mathrm{GHz}$, the transmission distance was $100 \mathrm{~m}$, the transmitting antenna aperture area was 2 $\mathrm{m}^{2}$, the receiving antenna area was $4 \mathrm{~m}^{2}$, and the input power was $4500 \mathrm{~W}$. The stable DC power output of the system was $468 \mathrm{~W}$, and the system efficiency reached $10.4 \%$.

\section{Conclusions}

1 According to long-distance wireless power transmission systems and their constituent units (including the transmitting antenna, space transmission, and the receiving end), performance evaluation indicators including size, power, and efficiency are proposed. Methods for testing the systems and components performance are constructed. An evaluation system for completely testing long-distance wireless power transmission systems was put forward.

2 Using a testing device, the laser-based and microwave-based systems were tested using the proposed testing methods. The optical power of the laser-based wireless power transmission system reached $185 \mathrm{~W}$, and the conversion efficiency of the system reached $7.9 \%$ for the transmission distance of $50 \mathrm{~m}$. The power of the microwave-based wireless power transmission system was $4500 \mathrm{~W}$, and the electricelectric conversion efficiency reached $10.4 \%$ for the transmission distance of $70 \mathrm{~m}$. The key parameters of the components and systems were obtained from these testing experiments, proving the feasibility of the proposed testing methods. The results provide a solid framework for the performance evaluation of long-distance wireless power transmission systems.

\section{Acknowledgements}

We are grateful to the anonymous reviewers who have contributed to the enhancement of the papers completeness with their valuable suggestions.

\section{Author's contributions}

This paper is completed with the cooperation of seven authors. WX proposed the research direction. LC and WC proposed the research methods. LP carried out the experimental verification. XW analyzed the data and wrote this manuscript. ZY carried out the translation work. WF proofread the paper. All authors read and approved the final manuscript.

\section{Funding}

None.

Availability of data and materials

The datasets used and/or analyzed during the current study are available from the corresponding author on reasonable request.

\section{Competing interests}

The authors declare that they have no competing interests.

Ethics approval and consent to participate

Not applicable.

Consent for publication

We agree to the publication of the paper

Author details

${ }^{1}$ Institute of System Engineering, Academy of Military Science, Beijing 100300, China. ${ }^{2}$ The PLA 32381 Troops, Beijing 100071, China.

Received: 20 July 2020 Accepted: 2 December 2020

Published online: 10 December 2020 
References

1. S. Dele, L. Zhenyu, W. Shichen, Z. Haiyang, The technology of wireless power transmission supporting space operation. Space Electron. Technol. 000(3), 66-70 (2013)

2. H. Xiujun, S. Zhenjiang, L. Liang, X. Hongyan, S. Dele, High efficiency long distance wireless energy transmission technology based on non-diffracted beams. Space Electron. Technol. 15(02), 79-83 (2018)

3. J. Howell, M. O'Neill, R. Fork, Advanced receiver/converter experiments for laser wireless power transmission. European Space Agency, (Special Publication) ESA SP, vol. 567 (2004), p. 187

4. J.E. Vandyke, S. Michael, A. Scott, A.J.E. Vandyke, Modeling Laser Effects on Multi-Junction Solar Cells. Using Silvaco ATLAS Software for Spacecraft Power Beaming Applications (2010)

5. H. Tao, Y. Suhui, Z. Haiyang, Z. Changming, X. Peng, H. Jiayin, W. Huaxin, Experiment of space laser energy transmission and conversion with high efficiency. China Laser 03, 253-258 (2013)

6. Q. Liang, Y. Yannan, Experimental research of laser wireless power transmission efficiency. Laser Technol. 38(05), 590-594 (2014)

7. M. Haihong, Research on microwave wireless power transmission technology in aerospace. Space Electron. Technol. 10(05), 590-594 (2014)

8. H. Xinbin, Solar power satellite and technology requirement for microwave wireless power transmission. Space Electron. Technol. 10(3), 57-60 (2014)

9. W.C. Brown, Performance characteristics of the thin-film, etched-circuit rectenna (1984)

10. Y. Xuexia, Z. Huawei, Z. Yongjin, Research progress in microwave wireless power transmission technologies and system efficiency evaluation. J. Shanghai Univ. (Nat. Sci.) 20(5), 549 (2014)

11. L. Wei, Research on the response characteristics and conversion efficiency of photovoltaic cells in laser wireless power transmission. PhD thesis, China Academy of Engineering Physics (2018)

12. M. Haihong, X. Hui, L. Xi, S. Linlin, A highly efficiency microwave wireless power transmission system. Space Electron. Technol. 13(1), 1-5 (2016)

13. C.F.W.J.X. Cong, W.G.Z.Y.M. Xiaoyu, Optimum the thickness of p-waveguide layer for high conversion efficiency of diode lasers. Acta Opt. 29(12), 3419-3423 (2009)

14. S. Yun-Fei, W. Zhen-Fu, L. Te, Y. Guo-Wen, Efficiency analysis of $808 \mathrm{~nm}$ laser diode array under different operating temperatures. Acta Phys. 66(10), 104202-104202 (2017)

15. Z. Yihao, Study of high efficiency high power semiconductor lasers. PhD thesis, Hebei University of Technology (2007)

16. G. Genwu, The research of microwave power transmission ground demonstration system. PhD thesis, Xian University of Posts and Telecommunications (2015)

\section{Publisher's Note}

Springer Nature remains neutral with regard to jurisdictional claims in published maps and institutional affiliations.

\section{Submit your manuscript to a SpringerOpen ${ }^{\circ}$ journal and benefit from:}

- Convenient online submission

Rigorous peer review

Open access: articles freely available online

- High visibility within the field

Retaining the copyright to your article

Submit your next manuscript at $\boldsymbol{\nabla}$ springeropen.com 